\title{
Problemas Enfrentados por los Extensionistas Rurales Argentinos en el Ejercicio de su Labor desde su Propia Perspectiva
}

\author{
Fernando Pablo Landini ${ }^{1}$
}

\begin{abstract}
Resumen: El presente artículo se propone identificar, describir y analizar los problemas que los extensionistas argentinos enfrentan en su práctica. Con este fin se aplicó una encuesta, la cual fue respondida por 219 extensionistas. Las respuestas fueron categorizadas con apoyo del software Atlas $\mathrm{Ti}$ a partir de la identificación de problemas que iban repitiéndose en distintas encuestas. Seguidamente, los resultados fueron cuantificados, considerándose presencia de la variable en una encuesta cuando la categoría que la expresaba había aparecido al menos una vez en ella. Mediante el uso del programa SPSS, también se estudió la asociación de los principales problemas identificados con diversas variables de interés. Se concluye que las dificultades más importantes enfrentadas por los extensionistas encuestados son (1) el individualismo, la desconfianza y la falta de asociaciones de productores, (2) los problemas para la comercialización y (3) la falta de apoyo público y de políticas de desarrollo rural.
\end{abstract}

Palabras-claves: Problemas, desarrollo rural, extensión rural, pequeños productores.

Abstract: This paper aims at identifying, describing and analyzing the problems faced by Argentine rural extensionists in their practice. To this end, a survey was conducted, which was replied by 219 extensionists. Problems appearing repeatedly in the open replies were categorized using Atlas Ti software. After that, results were quantified, to which end the presence of a specific problem described by a category at least once was considered as presence of the variable in that survey. Next, using SPSS software the relationship between the most important problems identified and other variables were studied. It is concluded that (1) individualism, distrust and lack of farmers' associations, (2) problems to sell the produce and (3) lack of public support and of rural development policies are the most frequently problems mentioned by the participants.

Key-words: Problems, rural development, rural extension, small farmers

Clasificación JEL: Q16. I + D.

1. Investigador del Consejo Nacional de Investigaciones Científicas y Técnicas (Conicet), Argentina. Docente e investigador de las Universidades de Buenos Aires (UBA) y de la Cuenca del Plata (UCP).

E-mail: landini_fer@hotmail.com 


\section{Introducción}

La extensión rural resulta de gran importancia para el desarrollo de la pequeña agricultura familiar $y$, en términos generales, para el desarrollo rural (ARDILA, 2010; MCLEOD y QAMAR, 2003). Por esta razón, llama la atención la existencia de escasos trabajos que aborden la temática de la extensión rural y sus problemas desde una perspectiva empírica. En efecto, lo que puede observarse, por un lado, son múltiples estudios que trabajan temas de interés para la extensión, pero sin tomarla a ella misma como objeto de investigación o reflexión. Así, se encuentran trabajos orientados a caracterizar o definir a la agricultura familiar, al campesinado o a alguna categoría asociada (e.g. SCHEINKERMAN, FOTI y ROMÁN, 2007; TORT y ROMÁN, 2005), a analizar estrategias de subsistencia y lógicas campesinas (e.g. CÁCERES, 1995; MANZANAL, 1993; SILVETTI y CÁCERES, 1998; STAGE y REKVE, 1998) o a estudiar procesos asociativos en el contexto de la pequeña producción agropecuaria (e.g. ELGUE y CHIARADÍA, 2007; FERNÁNDEZ, 1994; LOBOS, 2005). Por otro lado, también pueden encontrarse trabajos sobre extensión rural que, o plantean su dinámica y objetivos, en el sentido de materiales pedagógicos (e.g. DE SCHUTTER, 1982; CIMADEVILLA, 2004), o critican su carácter transferencista desde una posición prescriptiva de cómo debería ser su práctica (e.g. MARINO, 1993; SCHALLER, 2006), lo que sin dudas resulta muy valioso, pero no contribuye demasiado al estudio de las prácticas de extensión rural, sus limitantes y los factores que la condicionan.

Ante la necesidad de tomar a la extensión rural como objeto de estudio, resulta necesario señalar que este concepto ha sido criticado por diversos autores por la imagen que genera de transferencia de conocimientos y tecnologías de expertos a productores (CÁCERES, 2006; FREIRE, 1973; LANDINI y MURTAGH, 2011; LEEUWIS, 2004). No obstante, siendo que en la mayor parte de América Latina se trata de una noción de uso corriente, se opta por seguirla utilizando para referirse de manera genérica al rol que desempeñan los extensionistas. Por esto, su uso no debe tomarse como un indicador de la aceptación de una concepción transferencista de la extensión. Asumido lo anterior, cabe señalar que la extensión rural constituye una tarea compleja que no sólo incluye procesos centrados en cambios e innovaciones tecnológicas. Por el contrario, también refiere a la implementación de dinámicas participativas, a la gestión y facilitación de espacios grupales y asociativos, a la sensibilización ambiental, al apoyo a la comercialización y al acompañamiento de procesos de articulación territorial (LEEUWIS, 
2004; LEEUWIS y AARTS, 2011; MÉNDEZ, 2006; MEDEIROS y BORGES, 2007; SARAIVA y CALLOU, 2009; VAN WOERKUM, AARTS y VAN HERZELE, 2011). Ahora bien, dada la complejidad de su función y su formación fundamentalmente técnica, no resulta llamativo que los extensionistas rurales se enfrenten a una serie de problemas que reducen el impacto de sus acciones, algunos de los cuales escapan a su formación (LANDINI, MURTAGH y LACANNA, 2009).

En consecuencia, en este trabajo se presentan los resultados de una investigación que permitió identificar y cuantificar, desde la perspectiva de los extensionistas rurales argentinos que trabajan en el Instituto Nacional de Tecnología Agropecuaria (INTA) y en la Subsecretaría de Agricultura Familiar del Ministerio de Agricultura, Ganadería y Pesca (SAF), las problemáticas a las que se enfrentan en su práctica. En definitiva, lo que se busca al identificar y describir estos problemas es contribuir a generar estrategias para enfrentarlos. Más todavía, la presente investigación no sólo procura identificar estos problemas sino también cuantificarlos y relacionarlos con múltiples variables y procesos históricos, hecho que puede convertirlos en un instrumento con mayor probabilidad de incidir en quienes toman decisiones a nivel institucional. Por otra parte, también se hace entrar en diálogo estos resultados con trabajos relacionados realizados en Brasil, para fortalecer su utilidad para los lectores habituales de esta revista.

\section{Extensión rural en Argentina}

A continuación se describe brevemente la historia de la extensión rural en Argentina haciendo foco en el INTA, referente de mayor importancia en el país. De esta manera, se procura contextualizar y dar sentido a los resultados de este estudio. También se muestran paralelos con la historia de la extensión rural en Brasil, dada la existencia de múltiples similitudes. Partiendo de la base de que las instituciones de desarrollo no funcionan independientemente de las dinámicas, valores y objetivos sociales y políticos, diversos autores han procurado articular el devenir del INTA con los paradigmas de desarrollo rural más influyentes en cada momento histórico en Argentina (ALEMANY, 2003; CARBALLO, 2002, 2006). Por otra parte, también es necesario tener en cuenta la coexistencia, muchas veces conflictiva, de dos modelos de extensión que cruzan los diferentes períodos, uno más productivista, centrado en la transferencia de tecnologías, y otro orientado hacia la educación de la familia rural desde la perspectiva de la educación no formal (TORT, 2008). Este contrapunto, sin dudas, no resulta exclusivo de Argentina ya que, de la misma manera, DA ROS (2012) lo menciona como uno de los elementos que ha caracterizado a la extensión rural en Brasil. Finalmente, también es necesario tener en cuenta la posible presencia de estructuras y prácticas institucionales de períodos anteriores dentro de las dinámicas actuales de cualquier institución (MALFÉ, 1994). Esto, mencionado en este caso a nivel teórico para la extensión rural argentina, ha sido referido en Brasil insistentemente por diversos autores, quienes señalan la persistencia de enfoques de extensión transferencistas o difusionistas, cuando en realidad la asistencia técnica y la extensión rural (ATER) en Brasil es planteada institucionalmente como participativa y agroecológica (LELIS, COELHO y DIAS, 2012; SOUZA y GOMES, 2008; ZUIN, ZUIN y MANRIQUE, 2011).

Atendiendo a la organización histórica de la extensión en el INTA, se observa la existencia de cuatro períodos diferenciados (ALEMANY, 2003; CARBALLO, 2006; TORT, 2008). El primero se inicia en el año 1957, momento de la creación de la institución, y culmina en el 1976. Este período, que puede denominarse de extensión 'educativa' o 'desarrollista', se caracteriza por la adopción del modelo de extensión rural de los Estados Unidos sin hacerle prácticamente modificaciones (SCHALLER, 2006), algo que se repite en Brasil y en diversos países latinoamericanos (LELIS, COELHO y DIAS, 2012). Dentro de este modelo, la extensión es pensada desde la difusión y 
adopción de innovaciones productivas a partir de la educación de la familia rural, incluyéndose propuestas de trabajo diferenciadas para productores varones, mujeres y jóvenes, estrategia que articula aspectos técnicos y sociales, lo que requería un abordaje interdisciplinario. En este período, se observa un contraste entre la perspectiva difusionista hegemónica, que centraba el problema del desarrollo rural en el tradicionalismo de los productores, y una visión alternativa apoyada en desarrollos de la teoría de la dependencia (nacida en América Latina), expresada en las propuestas de FREIRE (1973)

El segundo período de la extensión rural en Argentina, que siguiendo a TORT (2008) va del año 1976 al 1990, se inicia con el gobierno militar y marca un cambio de enfoque en el modelo de trabajo en extensión. La atención se focaliza ahora exclusivamente en los productores agropecuarios y no en las familias, menos aun en las organizaciones y movimientos sociales del campo. El núcleo del accionar se orienta a la transferencia de paquetes tecnológicos por producto propios de la revolución verde, orientados mayormente a productores con cierto nivel de capitalización, incrementándose así la brecha entre minifundistas y capitalizados. Con el retorno de la democracia hacia mediados de los 80 se inicia un proceso de reorganización institucional orientado por ideas de descentralización, participación e integración, pero sin ponerse en cuestión el modelo transferencista.

El tercer período, que va del año 1990 al 2000, se caracteriza por la aplicación de políticas de ajuste estructural apoyadas en el paradigma neoliberal, las cuales llevaron al empobrecimiento de importantes sectores de la población. Esta situación lleva, por un lado, a proponer la privatización de la extensión pública en Argentina, en paralelo con el afán privatizador de los servicios de extensión en la mayor parte de los países latinoamericanos (THORNTON, 2006). En Brasil, en el año 1990, se disuelve la Empresa Brasileira de Assistencia Tecnica e Extensao Rural (EMBRATER), creada en el año 1974 (ALMEIDA, OLIVEIRA y XAVIER, 2010). En Argentina, el sistema nacional de extensión se mantiene pero sufre una importante merma presupuestaria. En este marco, surge de parte del INTA una propuesta para readecuarse al contexto. Esta propuesta se caracteriza por la definición de audiencias específicas que requerían estrategias de intervención diferenciadas, la incorporación de programas y proyectos de intervención como nueva modalidad de organización de las acciones, y la priorización de las PyMEs, el minifundio y la pobreza rural. Si bien la Unidad Minifundio del INTA se había creado en el 1987 para trabajar con minifundistas, en el 1990 se crea el Programa Integrado de Promoción de la Autoproducción de Alimentos (ProHuerta) para trabajar en seguridad alimentaria, en el 1993 se crea el Programa Social Agropecuario (PSA) (hoy parte fundamental de la SAF) para trabajar también con minifundistas, y el mismo año se empieza a implementar el Programa Federal de Reconversión Productiva para la Pequeña y Mediana Empresa (Cambio Rural).

El cuarto y último período, según plantean CARBALLO (2006) y TORT (2008), va aproximadamente del año 2000 a la actualidad y puede ser caracterizado como un momento de transición o 'salida' del modelo neoliberal. En este período surge un nuevo modelo de desarrollo rural que revaloriza el rol del estado en el fomento de procesos de desarrollo y conceptualiza a la innovación y a la competitividad como procesos sistémicos. Además, destaca el carácter localizado de los procesos desarrollo, espacios que presentan una diversidad de actores e instituciones. En este contexto, el INTA comienza a pensarse como facilitador de procesos de innovación tecnológica y organizacional, lo que lo lleva a distanciarse de la transferencia de tecnologías y a reconocer la existencia de multiplicidad de actores en los territorios con los que resulta necesario articularse. En paralelo, en Brasil, con la llegada el poder de Lula da Silva, aparece con fuerza la idea de una nueva extensión rural (ALMEIDA, OLIVEIRA y XAVIER, 2010), que se expresa en la Política Nacional de Assistência Técnica e Extensão Rural del año 2004 que propone una extensión rural participativa, agroecológica y orientada 
a responder a las necesidades de la agricultura familiar (MEDEIROS y BORGES, 2007)

\section{Materiales y método}

Para alcanzar los objetivos, se realizó una investigación cuali-cuantitativa (CONDE, 1990), aunque haciendo énfasis en el abordaje cuantitativo, buscando dar precisión numérica a los resultados, una cuestión de gran interés cuando se procura incidir en políticas públicas. A nivel epistemológico, el abordaje cualitativo sigue las premisas del paradigma constructivista, orientado a la descripción de la perspectiva de los actores. En cambio, la propuesta cuantitativa utiliza el paradigma post-positivista, el cual pone énfasis en la cuantificación y elaboración estadística de los resultados (GUBA y LINCOLN, 1994). En concreto, se realizó una encuesta a extensionistas rurales que trabajan en distintas instituciones que forman parte del sistema de extensión rural público de la Argentina. Entre julio de 2010 y marzo de 2011 se realizaron 219 encuestas, las cuales fueron enviadas y recibidas por email, para lo cual se contó con el aval de las autoridades provinciales de la SAF y del ProHuerta, y de diferentes niveles decisorios del INTA. Dado que se trató de una muestra incidental, al apoyarse en respuestas voluntarias, la misma no puede ser considerada como estadísticamente representativa de la totalidad de la realidad argentina. Por otra parte, reconociendo el perfil diferencial de quienes trabajan en el ProHuerta y en el INTA no ProHuerta (LANDINI, 2013a), se optó por considerar a ambos grupos por separado, incluyendo en la categoría ProHuerta a aquellos que, trabajando en el INTA, dedican el $50 \%$ o más de su tiempo a este programa.

La muestra está compuesta por 143 hombres y 76 mujeres. La mayor parte de ellos poseen título de ingeniero agrónomo $(60,3 \%)$, mientras que el $7,8 \%$ son veterinarios/as y el 7,8\% profesionales de las ciencias sociales. Por su parte, el 15,2\% no posee título universitario. El resto se divide en otras profesiones. Sus edades van de 25 a 65 años, con una media de 42,15. En cuanto a la experiencia en el trabajo como extensionistas, encontramos una media de 11,31 años. 106 de los encuestados trabajan en INTA, 72 en ProHuerta y 41 en la SAF. Teniendo en cuenta que INTA y ProHuerta poseen 1567 extensionistas, según informó la Coordinación Nacional de Transferencia y Extensión del INTA y que la SAF posee entre 800 y 900 técnicos de campo, se concluye que la muestra obtenida representa aproximadamente el 9\% de los extensionistas de estas instituciones (tomando 850 en el caso de la SAF). En cuanto a la distribución territorial, se optó por definir como región Cuyo a las provincias de Mendoza, San Juan y San Luis, como Noreste (NEA) a Chaco, Corrientes, Formosa y Misiones; como Noroeste (NOA) a Catamarca, Jujuy, La Rioja, Salta, Santiago del Estero y Tucumán; como Pampeana a Buenos Aires, Córdoba, Entre Ríos, La Pampa y Santa Fe; y como Patagonia a Chubut, Neuquén, Río Negro, Santa Cruz y Tierra del Fuego. Teniendo en cuenta 5 casos perdidos, Cuyo contó con 14 respuestas, NEA con 46, NOA con 61, Pampeana con 80 y Patagonia con 13.

La encuesta se dividió en dos partes. La primera incluyó preguntas cerradas como sexo, edad, años de experiencia en el área de extensión, provincia de desempeño laboral, etc., y seis preguntas abiertas, de las cuales se trabaja en este artículo con las dos primeras: 1. "Según su experiencia ¿cuáles son los principales problemas que tienen los pequeños productores para progresar y salir adelante?"; y 2. “Muchas veces los proyectos de extensión y de desarrollo rural con pequeños productores no logran los resultados que se esperan. Además de lo mencionado en la pregunta anterior, ¿qué otras dificultades surgen en el trabajo de extensión?" En ambas preguntas se optó por mencionar que en la respuesta era posible "incluir dificultades de toda clase (sociales, psicológicas, económicas, culturales, productivas, políticas, institucionales, etc.)", con el objetivo de encuadrar la pregunta desde una perspectiva amplia, no exclusivamente productiva. Respecto del concepto 'pequeño productor', no se estableció una definición a priori. Al contrario, se 
permitió que los encuestados utilizaran su propia concepción, contextualmente situada.

Para identificar y organizar los problemas señalados por los extensionistas se procedió a leer las encuestas y a construir categorías para agruparlos con el apoyo del software Atlas Ti. Como las categorías utilizadas no existían $a$ priori, éstas tuvieron que definirse y precisarse durante el proceso de categorización. Con este objetivo, para cada una de ellas se construyó una definición operativa de su contenido, donde se incluyó también cómo se debía proceder en casos específicos cuya categorización (o no categorización) podía ser dudosa o discutible, con el fin de utilizar siempre el mismo criterio de inclusión/exclusión. Así, la definición de las categorías no fue firme hasta que se terminó de categorizar todo el material. Por esta razón, con las categorías definitivas se procedió a una nueva lectura de todas las respuestas, con el fin de aplicar sistemáticamente a todo el material las categorías a las que se había arribado. Seguidamente, para chequear la consistencia de cada una de ellas, se procedió a una lectura de todos los fragmentos, lo que permitió cerciorarse de que todos los segmentos de texto incluidos respetaban la definición correspondiente y poseían coherencia interna. Finalmente se revisaron aquellas categorías que, al poseer contenidos similares, podían generar dudas de categorización entre ambas. Así, se decidió unificar aquellas para las cuales no se pudo construir criterios que clarificaran de manera definitiva las diferencias entre una y otra, incluyéndose criterios de diferenciación adicionales cuando esto fue posible. En la primera parte del análisis que sigue, se enumeran y cuantifican los problemas a los que se enfrentan los extensionistas en su práctica, para luego hacer una descripción más detallada a nivel cualitativo. La enumeración alcanza a los problemas mencionados por al menos el 5\% de la nuestra y la descripción cualitativa a los 10 más significativos. A continuación, se procede a analizar la asociación de estos problemas con variables como sexo, edad, institución en la que se desempeñan funciones, región de la Argentina donde se trabaja, máximo nivel educativo alcanzado, título universitario obtenido y años de experiencia en el trabajo de extensión. Las instituciones consideradas fueron INTA, ProHuerta y SAF. En cuanto a los niveles educativos, se asignó 1 a quienes tenían primario completo, 2 a secundario, 3 a terciario, 4 a universitario, 5 a cursos de postgrado, 6 a especialización, 7 a maestría y 8 a doctorado. Respecto de los títulos universitarios, se diferenció entre ingenieros agrónomos, veterinarios, profesionales de las ciencias sociales y otros. Estos datos fueron volcados al software SPSS 17.0. Para cada una de las categorías referidas a problemas, se generó una variable dicotómica que reflejara la presencia o ausencia de menciones a dichas temáticas en cada una de las encuestas. Ahora bien, para hacer el análisis de asociación entre variables, sólo se trabajó con aquellos problemas mencionados espontáneamente por más del 10\% de los encuestados.

Para relacionar los problemas con variables nominales como sexo, institución, región y título universitario, se utilizó el estadístico Chi cuadrado $\left(\chi^{2}\right)$. En los casos en los que los valores esperados fueron menores a 5 en más del $20 \%$ de los casilleros, se optó por utilizar en su reemplazo el Coeficiente de Contingencia. Por su parte, para relacionar los problemas con variables escalares como edad y experiencia en extensión, se utilizó el estadístico T de Student para la comparación entre grupos. Para el caso de la variable ordinal 'máximo nivel educativo alcanzado', siguiendo procedimientos usuales en el trabajo con escalas likert con 5 o más niveles de respuesta, se optó también por trabajarla como escalar.

\section{Resultados y discusión}

\subsection{Listado de problemas}

A continuación se presenta el listado de los problemas para el trabajo de extensión y para el desarrollo de los pequeños productores mencionados por los 219 encuestados. Los mismos se presentan ordenados según la cantidad de extensionistas que los mencionan en la muestra. 
Tabla 1. Problemas para el trabajo de extensión y para el desarrollo de los pequeños productores

\begin{tabular}{|c|c|c|}
\hline Problemas & Casos & Porcentaje \\
\hline 1. Individualismo, desconfianza y falta de asociaciones de productores. & 101 & $46,12 \%$ \\
\hline 2. Problemas para comercializar o vincularse con los mercados. & 59 & $26,94 \%$ \\
\hline 3. Falta de apoyo público o institucional, o de políticas de desarrollo rural. & 57 & $26,03 \%$ \\
\hline 4. Falta de tierra, tierra improductiva o problemas de tenencia. & 53 & $24,20 \%$ \\
\hline 5. Proyectos e iniciativas planificadas 'desde arriba' o que no responden a las necesidades o cultura de los beneficiarios. & 51 & $23,29 \%$ \\
\hline 6. Productores con actitud asistencialista, oportunista, pasivos o sin cultura del trabajo. & 46 & $21,00 \%$ \\
\hline 7. Falta de créditos para la actividad productiva. & 45 & $20,55 \%$ \\
\hline 8. Falta de capital para la producción, de inversión o de infraestructura predial & 42 & $19,18 \%$ \\
\hline 9. Productores con tecnología o manejo productivo inadecuado o tradicional. Falta de conocimientos productivos. & 41 & $18,72 \%$ \\
\hline 10. Clientelismo, asistencialismo o paternalismo de parte del gobierno u otras instituciones. & 40 & $18,26 \%$ \\
\hline 11. Políticas y proyectos de desarrollo o extensión rural cambiantes, cortoplacistas o sin seguimiento o continuidad. & 35 & $15,98 \%$ \\
\hline 12. Volumen de producción bajo, falta de escala. & 33 & $15,07 \%$ \\
\hline 13. Falta de articulación o problemas para la articulación interinstitucional. & 30 & $13,70 \%$ \\
\hline 14. Escasa participación y apropiación de los proyectos de extensión y desarrollo rural por parte de los beneficiarios. & 29 & $13,24 \%$ \\
\hline 15. Falta de infraestructura extrapredial para la producción, incluyendo caminos. & 29 & $13,24 \%$ \\
\hline 16. Productores con bajos ingresos o baja rentabilidad. & 28 & $12,79 \%$ \\
\hline 17. Productores con falta de mirada empresarial o con problemas para la gestión empresarial. & 27 & $12,33 \%$ \\
\hline 18. Emigración de productores a las zonas urbanas, jóvenes sin interés en la agricultura que emigran. & 25 & $11,42 \%$ \\
\hline 19. Falta de servicios públicos (electricidad, agua, gas, etc.). & 25 & $11,42 \%$ \\
\hline 20. Problemas de salud de la población rural y falta de cobertura adecuada en las áreas de salud, educación o vivienda & 25 & $11,42 \%$ \\
\hline 21. Productores con resistencia al cambio. Falta de adopción de tecnologías. & 25 & $11,42 \%$ \\
\hline 22. Complejidad del campo de la extensión rural y falta de equipos interdisciplinarios en el trabajo de extensión. & 24 & $10,96 \%$ \\
\hline 23. Falta de recursos económicos para proyectos y para el trabajo de extensión. & 24 & $10,96 \%$ \\
\hline 24. Políticas o proyectos de extensión o desarrollo rural focalizados, productivistas o que no se interesan ni evalúan variables sociales. & 23 & $10,50 \%$ \\
\hline 25. Falta de agua para producción o consumo (aquí no se la considera como servicio público sino en cuanto a su disponibilidad). & 21 & $9,59 \%$ \\
\hline 26. Productores con bajo nivel educativo. & 20 & $9,13 \%$ \\
\hline 27. Dificultades de acceso o situación de aislamiento de los productores. & 19 & $8,68 \%$ \\
\hline 28. Extensionistas con falta de formación o conocimientos. & 19 & $8,68 \%$ \\
\hline 29. Falta de legislaciones apropiadas para la agricultura familiar. & 19 & $8,68 \%$ \\
\hline 30. Políticas públicas y proyectos de extensión y desarrollo rural desarticulados. & 19 & $8,68 \%$ \\
\hline 31. Presión de otras actividades económicas frente a la agricultura familiar. & 18 & $8,22 \%$ \\
\hline 32. Bajos precios de venta de productos de la agricultura familiar. & 13 & $5,94 \%$ \\
\hline 33. Productores con alto nivel de pobreza o necesidades básicas insatisfechas. & 12 & $5,48 \%$ \\
\hline 34. Productores con baja autoestima. & 12 & $5,48 \%$ \\
\hline 35. Extensionistas autoritarios o no participativos. & 12 & $5,48 \%$ \\
\hline 36. Degradación de suelos y recursos naturales. & 11 & $5,02 \%$ \\
\hline $\begin{array}{l}\text { 37. Falta de investigación y de tecnologías apropiadas para la agricultura familiar o falta de articulación entre las áreas de } \\
\text { investigación y extensión. }\end{array}$ & 11 & $5,02 \%$ \\
\hline 38. Incertidumbre de precios de venta de productos o incertidumbre climática. & 11 & $5,02 \%$ \\
\hline 39. Inclemencias climáticas, plagas o clima adverso. & 11 & $5,02 \%$ \\
\hline
\end{tabular}

Fuente: Autor.

Focalizando la reflexión en los problemas más mencionados (aquellos señalados espontáneamente en más del 10\% de los casos), se observa un amplio grupo que puede ser referido al área de las políticas y las instituciones relacionadas con los procesos de desarrollo rural. En primer lugar, se señala (3) la falta de apoyo público o de políticas para el desarrollo rural, lo que se complementa con (5) políticas y proyectos no participativos, (11) cambiantes y cortoplacistas, y (24) focalizados o productivistas. Además, se agrega la existencia de prácticas (10) asistencialistas, paternalistas e incluso clientelares, (23) la falta de recursos para el trabajo de extensión y la (13) desarticulación entre las instituciones vinculadas con el desarrollo rural. Así, la dimensión político-institucional 
aparece como un fuerte limitante del desarrollo desde la mirada de los encuestados.

Visto esto, resulta interesante reflexionar sobre la relación entre lo encontrado en las encuestas, y los modelos de extensión y desarrollo rural hegemónicos en Argentina en las distintas épocas. En primer lugar, se observan preocupaciones muy en tono con el momento actual, como son aquellas que reclaman políticas y proyectos más participativos, articulación interinstitucional a nivel local y proyectos no asistencialistas. La cuestión de la falta de políticas de desarrollo rural, por su parte, trae una importante pregunta: iserá que en el momento actual los extensionistas, pese al cambio de modelo político y de desarrollo a nivel nacional, siguen percibiendo la falta efectiva de políticas públicas de desarrollo rural como sucedía en el contexto de ajuste de los 90s? ¿O será que consideran a las políticas actuales como insuficientes? En todo caso, no hay que pensar que se trata de alternativas necesariamente contradictorias, pudiendo existir percepciones mixtas.

Como segunda área de interés aparecen diversos problemas que ponen el eje en limitaciones de los productores. Así, se los describe como (1) individualistas y desconfiados, (6) pasivos, oportunistas o sin cultura del trabajo, (9) faltos de conocimientos productivos apropiados, (14) con escasa participación e implicación en trabajos de extensión, (17) con falta de mirada empresarial y (18) con resistencia al cambio y a la adopción de tecnologías. Visto así, el productor parece configurarse como un problema fundamental para el desarrollo rural y para el éxito de los proyectos de extensión, desde el punto de vista de los extensionistas. En comparación, los extensionistas aparecen como problema en escasas oportunidades, describiéndoselos en menos del 10\% de los casos como faltos de formación o con tendencias autoritarias. Así, puede concluirse que existe una fuerte tendencia a responsabilizar a los productores por los problemas de la extensión, minimizándose el rol que pueden tener los mismos extensionistas como causantes o como soportes de estos problemas. Esto lleva a dos reflexiones de interés. Por un lado, se observa la persistencia de una visión difusionista o rogeriana de los pequeños productores, propia de la primera etapa, la cual los caracteriza como individualistas, tradicionalistas y resistentes al cambio. Por otro lado, también se percibe que, si bien el modelo hegemónico de extensión hoy supuestamente está orientado al extensionista como facilitador de procesos de innovación, aquí parece seguir centrando en la propuesta de transferencia de tecnologías, lo que induce a evaluar a los productores en términos de su pasividad o resistencia a estas nuevas tecnologías que se le ofrecen.

También puede mencionarse una tercera área problemática, de menor importancia cuantitativa, relacionada con la escasa dotación de capital que refiere a (7) la falta de créditos, (8) la falta de infraestructura predial y de inversiones, y a la (15) falta de infraestructura extrapredial, tanto para el transporte como para riego o para el incremento del valor agregado. Finalmente, también se encuentra un cuarto grupo de problemas relacionados con la comercialización y el mercado, que incluye fundamentalmente el problema 2, que refiere a esta cuestión directamente. Esto, a su vez, se relaciona con un (12) bajo volumen de producción (falta de escala), lo que deriva en (16) bajos ingresos. En relación a esto, el problema 1 referido al individualismo y a la falta de iniciativas asociativas, aparece como un limitante de gran importancia, ya que esta estrategia es usualmente descripta por los encuestados como forma de enfrentar los problemas de comercialización, lo que se apoya en la argumentación de múltiples autores (ELGUE y CHIARADÍA, 2007; HENZ, 2010; LOBOS, 2005; TORT, 2005; TORT y LOMBARDO, 1996).

A continuación se presenta en una tabla el análisis cuantitativo de estas cuatro áreas problemáticas surgidas de la agregación de los problemas mencionados por los encuestados. En ella, los porcentajes refieren a los encuestados que mencionan al menos uno de los problemas correspondientes a cada área problemática. 
Tabla 2. Áreas problemáticas para el trabajo de extensión y para el desarrollo de los pequeños productores

\begin{tabular}{lcc}
\hline \multicolumn{1}{c}{ Áreas problemáticas } & Casos & Porcentaje \\
\hline A. Políticas e instituciones de desarrollo rural & 148 & 67,6 \\
B. El productor como problema & 144 & 65,8 \\
C. Escasa dotación de capital e infraestructuras & 91 & 41,6 \\
D. Comercialización, ingresos y mercados & 88 & 40,2 \\
\hline
\end{tabular}

Fuente: Autor.

\subsection{Descripción cualitativa de los problemas identificados}

El problema más mencionado es el (1) individualismo, desconfianza y falta de asociaciones de productores, el cual incluye un amplio rango de contenidos. Estos van desde la descripción de los productores como sujetos individualistas, desconfiados o sin espíritu asociativo, hasta el señalamiento de la falta de asociaciones, principalmente pensadas como alternativa para aumentar el volumen y colocar productos en el mercado. Tomando citas textuales de las encuestas, encontramos como problemas "individualismo y desconfianza hacia las iniciativas organizativas tales como grupos, cooperativas, etc.", lo que lleva a "dificultades para adaptarse a las actuales economías de mercado, integrar la producción y alcanzar economías de escala". Como se mencionó, la identificación de este problema parece asociarse, en diferentes casos, con una concepción difusionista del desarrollo rural. Además, resulta de pensar a partir de un interés de intervención específico: el trabajo asociativo entre productores

En segundo lugar, se observan (2) problemas para comercializar o vincularse con los mercados, lo que se expresa en términos de "marginalidad de la comercialización" o "comercialización precaria". Esto es explicado a partir de "capacidades limitadas a la hora de negociar o gestionar", a causa de escasos volúmenes de producción, la presencia de "muchos intermediarios" o la "no integración en la cadena". Por su parte, la (3) falta de apoyo público o institucional o de políticas de desarrollo rural hace referencia, en términos generales, a que "faltan políticas integrales que atiendan al sector, que apoyen sus actividades", lo que se concreta con frases como la "falta de políticas de estímulo para estos productores" o de "subsidios o créditos de fácil acceso".

En cuarto lugar, encontramos la (4) falta de tierra o problemas de tenencia. Esta dificultad aparece de manera espontánea en casi una de cada cuatro encuestas. Dentro de esta categoría, lo que se observa más frecuentemente son referencias a la falta de "regularidad de tenencia de tierra". Esto se expresa en que, como señala un encuestado, "en la mayoría de los casos no tienen siquiera título de propiedad". No obstante, también se mencionan casos en los cuales el problema no es de tenencia sino de superficie, ya que se trata de "propiedades pequeñas" o "predios muy chicos para desarrollar su labor productiva". Finalmente, también hay casos, pocos por cierto, en los cuales lo que más destaca es la falta de productividad del suelo más que la tenencia o la superficie: "estos predios [los de los pequeños productores] en general están ubicados en áreas que son menos propicias productivamente, donde la dotación de recursos naturales es menor". Resulta importante mencionar que la temática de la tierra no aparece como preocupación destacada en ninguna de las distintas etapas de la extensión en la Argentina, tal vez por constituir una temática crítica que pone en discusión la concentración de la tierra y el rol de los grandes capitales.

En quinto lugar, también con más del $20 \%$ de menciones, se señala como problema la existencia de (5) proyectos e iniciativas planificadas 'desde arriba' o que no responden a las necesidades o cultura de los beneficiarios. Los comentarios respecto de este punto poseen gran variabilidad por la multiplicidad y el carácter contextual 
de los ejemplos a los que se hace referencia. No obstante, se señala que "los proyectos en general fracasan porque fueron pensados desde la institución y no desde los productores", es decir que "las soluciones a los problemas, no se construyen con la gente" ya que "la mayoría de los proyectos están pensados desde fuera del propio lugar donde se actúa". En definitiva, se trata de un llamado de atención a programas que son generados a nivel centralizado sin permitir la especificación contextual de las iniciativas. Ahora bien, pese a que en la mayoría de los casos se insiste en la determinación institucional de esta modalidad de trabajo, también hay algunos casos en los cuales se reconoce el rol que pueden jugar los extensionistas mismos en este proceso. Como señala uno de ellos: "la mayoría de los programas son 'bajados' a los pequeños productores, desde el profesional al productor. Modificar el esquema no es un problema del productor sino de la formación profesional". Como se mencionó, la identificación de esta situación como problema por parte de los extensionistas, bien parece relacionarse con un modelo de hacer extensión que pone el foco en el surgimiento de iniciativas 'desde abajo', es decir, en el rol activo de los productores en los procesos de desarrollo.

En sexto lugar aparece como problema la (6) actitud asistencialista, oportunista, la pasividad o la falta de cultura del trabajo de los productores, lo que muchas veces se expresa en la referencia a la pérdida de la voluntad de esforzarse para procurar la propia subsistencia a partir de la existencia de ayudas o planes sociales. Como argumenta un encuestado "con los planes sociales viven sin trabajar y en muchos casos alquilan las chacras, no hay cultura del trabajo". Así, se describe un posicionamiento pasivo en el contexto del cual "las soluciones que esperan las tienen que dar los profesionales", ya que "al no generar recursos propios se espera siempre ayuda externa". No obstante, los planes sociales no son el único argumento que se menciona para explicar esta dinámica. También se hace referencia a creencias fatalistas generadas en el contexto de la lucha por la supervivencia en la cual "se genera una sociedad o grupo de gente resignada a la suerte", que "mayoritariamente están en la creencia que por ser pequeños no pueden salir adelante". Así, queda claro que falta la actitud emprendedora que muchos proyectos esperan de ellos. Aquí, parecen articularse dos realidades. Primero, la persistencia de una visión negativa de la cultura y perspectiva de los productores, derivada de postulados difusionistas, característicos de la primera etapa de desarrollo de la extensión en Argentina. Y segundo, la existencia de múltiples programas de características asistencialistas derivados de las políticas compensatorias de los 90, ampliados luego de la crisis del 2001-2002 y transformados actualmente en políticas estables de transferencia de ingresos bastante universalizadas, como es el caso de la Asignación Universal por Hijo. Así, se percibe a los productores como sujetos pasivos y con actitudes asistencialistas a partir de la interpretación de los efectos de las políticas asistenciales implementadas.

En séptimo lugar, con menciones en más del $20 \%$ de las encuestas, aparece la (7) falta de créditos, fundamentalmente para la actividad productiva. Como puede intuirse, se trata de una categoría transparente que focaliza en los "problemas para el financiamiento" de los pequeños productores, siendo un "productor no bancarizable". Así, "el sistema financiero convencional los excluye y el sistema financiero institucional es burocrático y llega a destiempo", por lo que deben pagar tasas mucho más altas para obtener créditos informales.

El octavo problema mencionado es la (8) falta de capital para la actividad productiva, lo que se complementa con la falta de inversiones y de infraestructura predial. Esto refiere, primero, a que al pequeño productor le faltan "infraestructuras básicas para el manejo productivo" debido a su situación de restricción económica. Así, "los ingresos no les posibilitan la reinversión en la empresa" y le "faltan [...] recursos económicos para invertir en tecnologías". Esto genera un círculo vicioso en el cual la escasa dotación de capital no permite aumentar ni los rindes ni los ingresos lo cual no permite generar excedentes para reinvertir. 
En noveno lugar se ubica la (9) falta de conocimientos productivos de los agricultores familiares, los cuales se perciben como teniendo tecnologías o manejos productivos inadecuados o tradicionales. Esta visión se vincula profundamente con una concepción tradicional de la extensión asociada a modelos que ponen el foco en la transferencia de tecnologías. Dentro de esta área problemática se observan un conjunto de descripciones en las cuales se menciona que los productores no poseen conocimientos y/o prácticas productivas consideradas adecuadas por los extensionistas. Esto incluye desde referencias relativamente asépticas a la "falta de capacitación" o a la "falta de tecnologías apropiadas" hasta comentarios connotados de manera negativa como "sucesivos años de trabajo con tecnologías obsoletas". En este sentido, aparecen descripciones referidas a prácticas concretas como la existencia de "bajos rendimientos por suelos desgastados por monocultivo de muchos años y los laboreos con herramientas obsoletas como arado de mancera que contribuye a su deterioro". Ahora bien, estas prácticas consideradas inapropiadas se explican en las encuestas de dos maneras. Una hace énfasis en la resistencia de los productores a la adopción de nuevas tecnologías (un factor interno, individual y personal). La otra hace referencia a condiciones de contexto que limitan las posibilidades de los productores. Respecto de la primera, se argumenta que los agricultores "son reacios a incorporar nuevas tecnologías (realizan los cultivos como hace 50 años atrás, como lo hacían sus abuelos)". En contraste, hay otros que argumentan que hay "falta de recursos económicos para invertir en tecnologías". Esto resulta interesante, ya que muestra dos alternativas de interpretación de la misma situación, una más tradicional, derivada de los postulados difusionistas que proyectan el problema en la interioridad de los productores, y otra que reconoce la complejidad y los determinantes del uso de tecnologías.

Finalmente, el décimo problema más mencionado es la (10) existencia de prácticas clientelares, asistenciales o paternalistas de parte del gobierno o de otras instituciones como ONGs. En este contexto, no se argumenta que los productores adopten actitudes de carácter asistencialista, como se mencionó en el problema seis, sino que se hace énfasis, fundamentalmente, en ciertas prácticas o estrategias de los distintos niveles e instituciones del gobierno. Así, se hace referencia a la existencia de prácticas clientelares o lógicas políticas locales que inciden de manera negativa en los procesos de desarrollo. En este sentido, a nivel general, encontramos frases como: "los contextos políticos (partidarios) particulares de cada lugar muchas veces dificultan las articulaciones o acciones llevadas a cabo en el territorio". A esto se suma el "paternalismo institucional planteado desde los distintos gobiernos", lo que lleva a que las "poblaciones rurales se muevan al compás de las ayudas políticas de los gobiernos". Sin dudas, aquí se evidencia el contraste entre una lógica técnica, derivada de los principios de las disciplinas científicas que la sustentan, y la lógica propia de los actores políticos, articulada a partir de otros intereses y prioridades (LAPALMA, 2001).

En el análisis interpretativo realizado en este apartado, se señaló la aparición, en diferentes momentos, de problemas que sugieren la existencia de una concepción difusionista del trabajo de extensión en Argentina. En el contexto brasileño, son diferentes los autores que también han hecho referencia a este problema (e.g. LELIS, COELHO y DIAS, 2012; ZUIN, ZUIN y MANRIQUE, 2011). En este sentido, SOUZA y GOMES (2008) argumentan que si bien en el año 2004 el Ministério de Desenvolvimento Agrário estableció un cambio de modelo de extensión, esto ha sido más bien un cambio formal, ya que persisten viejas prácticas focalizadas en la comunicación persuasiva. En esta línea, ALMEIDA, OLIVEIRA y XAVIER (2010) señalan que si bien se busca una integración entre la dimensión técnica y la social en la labor de extensión, los extensionistas siguen mostrando un claro énfasis productivo. En definitiva, como comentan TAVEIRA y OLIVEIRA (2008), "observa-se que ainda persiste um distanciamento entre o discurso renovador e a prática presa a velhos dogmas difusionistas" (p. 11). 
Focalizando ahora en los problemas mencionados por los extensionistas, también existen autores que han señalado en Brasil dificultades relacionadas con el individualismo y la falta de orientación asociativa de los agricultores familiares. En este sentido, SARAIVA y CALLOU (2009), trabajando con comunidades pesqueras de Pernambuco, han mencionado que los niveles de organización de estos productores son muy frágiles. Por su parte, BOAS y GOLDEY (2005), analizando la participación de campesinos en organizaciones de agricultores familiares en Minas Gerais, concluyen que los extensionistas rurales tienen un largo camino para generar una mentalidad cooperativa entre los productores, ya que estos tienden a ser muy individualistas.

Respecto del problema de la comercialización dela producción, sibien nose trata de algoindicado de manera insistente en la bibliografía, SILVA y LEITÃO (2009) lo reconocen como una dificultad característica de los productores no estructurados en Brasil. Por otra parte, otros autores también han señalado, como en el caso argentino, falta de apoyo público o institucional a los agricultores familiares en lo que hace a acciones de apoyo al desarrollo rural (SEPULCRI y PAULA, 2008). En este sentido, AQUINO y TEIXEIRA (2005) señalan que, al menos en el nordeste brasilero, pese a la existencia del PRONAF (Programa Nacional de Fortalecimento da Agricultura Familiar), la mayor parte de los productores no tienen acceso real a créditos, ya que los requisitos establecidos no permiten acceder al programa a la mayor parte de los productores familiares. Además, en esta argumentación también se observa una crítica a la existencia de proyectos, programas o políticas que no se adecuan a las necesidades o a la realidad que viven aquellos que deberían ser sus beneficiarios.

En resumen, se observa que buena parte de los problemas mencionados en el análisis del caso argentino también aparecen señalados en Brasil. Sin embargo, no resulta aquí posible comparar la importancia cuantitativa que éstos pueden tener en cada contexto. Ahora bien, algo que resulta interesante de señalar, es la mención frecuente en la literatura brasileña del número insuficiente de técnicos con los que cuentan las distintas EMATER (Empresa de Assistência Técnica e Extensão Rural) (e.g. SALVADOR, 2010), lo que puede agravarse con la falta de reposición de personal (SEPULCRI y PAULA, 2008). Frente a esto, THORNTON (2006) recuerda que las realidades de las distintas EMATER son diferentes. De cualquier manera, resulta importante señalar que aquí surge un interesante contraste con Argentina, donde casi ningún extensionista ha señalado esto como problema, además de no aparecer con frecuencia en la literatura argentina que analiza la extensión.

\subsection{Variables asociadas a los problemas identificados}

En la tabla 3 se asocian las áreas problemáticas y los problemas individuales que fueron mencionados en más del $10 \%$ de las encuestas con diversas variables de interés.

Comenzando con el análisis de la relación entre las variables estudiadas y las cuatro áreas problemáticas identificadas, se observa que no existen datos para sostener la existencia de relación entre estas áreas y la institución en la que trabajan los extensionistas, su nivel educativo y su experiencia en el trabajo de extensión. Resulta particularmente llamativo que no existan diferencias estadísticas a nivel de la institución a la que pertenecen los extensionistas en ninguno de los casos, ya que el perfil diferencial de las tres instituciones abordadas lo hacía suponer. Por ejemplo, sería probable que los técnicos de la SAF y del INTA mencionaran más problemas de comercialización (área D) que los de ProHuerta, ya que estos últimos no incluyen esta problemática dentro de sus lineamientos de trabajo.

Por su parte, el sexo está estadísticamente asociado al área 'El productor como problema'. En concreto, son menos los hombres que mencionan problemas contenidos en esta área (59\%) que las mujeres $(78 \%)$, sin que pueda presentarse aquí un argumento explicativo razonable. Respecto de la edad, encontramos la existencia de relación estadística con las áreas ‘El productor 
Tabla 3. Variables asociadas a los problemas identificados

\begin{tabular}{|c|c|c|c|c|c|c|c|}
\hline \multirow{2}{*}{$\begin{array}{l}\text { Áreas } \\
\text { problema }\end{array}$} & Sexo & Edad & Institución & Región & Nivel educativo & Título & Experiencia \\
\hline & $\chi^{2}=$ & $t=$ & $\chi^{2}=$ & $\chi^{2}=$ & $t=$ & $\chi^{2} /$ Coef & $t=$ \\
\hline A. & $0,18(1)$ & $-1,12$ & $0,78(2)$ & $11,58(4)^{*}$ & $-0,832$ & $11,82(4)^{*}$ & $-1,91$ \\
\hline B. & $7,29(1)^{* *}$ & $1,99^{*}$ & $3,97(2)$ & $1,71(4)$ & 0,427 & $3,81(4)$ & 0,71 \\
\hline C. & $0,03(1)$ & $-1,28$ & $0,17(2)$ & $3,33(4)$ & $-0,01$ & $7,25(4)$ & $-0,73$ \\
\hline D. & $0,18(1)$ & $-2,21^{*}$ & $3,33(2)$ & $3,99(4)$ & $-1,66$ & $14,05(4)^{* *}$ & $-1,59$ \\
\hline 1. & $5,12(1)^{*}$ & 1,23 & $2,05(2)$ & $4,03(4)$ & $-0,60$ & $9,83(4)^{*}$ & 0,29 \\
\hline 2. & $3,12(1)$ & $-1,90$ & $0,24(2)$ & $0,31(4)$ & $-2,16^{*}$ & $0,25^{* *}$ & $-0,06$ \\
\hline 3. & $5,45(1)^{*}$ & $-0,86$ & $7,21(2)^{*}$ & $13,10(4)^{*}$ & $-0,27$ & $0,23^{*}$ & $-1,34$ \\
\hline 4. & $0,04(1)$ & $-1,05$ & $4,27(2)$ & $6,68(4)$ & 0,42 & 0,19 & $-0,25$ \\
\hline 5. & $0,60(1)$ & $-0,74$ & $1,51(2)$ & $1,41(4)$ & $-1,24$ & 0,14 & $-1,90$ \\
\hline 6. & $0,29(1)$ & $-0,05$ & $0,12(2)$ & $7,22(4)$ & $-0,15$ & 0,06 & $-0,23$ \\
\hline 7. & $2,63(1)$ & $-1,51$ & $5,55(2)$ & $1,84(4)$ & $-1,70$ & 0,21 & $-1,56$ \\
\hline 8. & $3,83(1)$ & $-0,58$ & $0,27(2)$ & $5,02(4)$ & 0,26 & 0,16 & $-0,01$ \\
\hline 9. & $0,42(1)$ & 0,33 & $0,66(2)$ & $4,04(4)$ & 1,68 & 0,10 & $-0,09$ \\
\hline 10. & $0,70(1)$ & $-0,32$ & $6,20(2)^{*}$ & $15,89(4)^{* *}$ & 0,33 & 0,08 & $-0,82$ \\
\hline 11. & $0,69(1)$ & $-1,52$ & $2,25(2)$ & $0,78(4)$ & 0,33 & 0,07 & $-0,71$ \\
\hline 12. & $0,95(1)$ & $-1,64$ & $9,12(2)$ & $9,35(4)$ & $-0,71$ & $0,24^{*}$ & $-2,23^{*}$ \\
\hline 13. & $3,59(1)$ & 1,48 & $0,54(2)$ & $2,46(4)$ & $-1,13$ & 0,12 & 0,96 \\
\hline 14. & $0,66(1)$ & $2,13^{*}$ & $5,62(2)$ & $6,72(4)$ & 0,65 & 0,14 & 0,92 \\
\hline 15. & $0,01(1)$ & $-0,50$ & $6,20(2)^{*}$ & $9,47(4)$ & 0,15 & $0,25 * *$ & $-0,18$ \\
\hline 16. & $2,50(1)$ & $-1,03$ & $2,88(2)$ & $5,03(4)$ & 0,66 & 0,08 & $-1,61$ \\
\hline 17. & $0,35(1)$ & $-0,49$ & $2,59(2)$ & $3,95(4)$ & 1,20 & 0,13 & $-0,54$ \\
\hline 18. & $0,56(1)$ & $2,89 * *$ & $0,87(2)$ & $14,71(4)^{* *}$ & $-1,10$ & 0,17 & 0,95 \\
\hline 19. & $5,65(1)^{*}$ & $-0,28$ & $0,20(2)$ & $8,90(4)$ & $-1,34$ & 0,15 & 0,17 \\
\hline 20. & $3,73(1)$ & 0,21 & $0,91(2)$ & $20,50(4)^{* *}$ & 0,85 & 0,09 & $-0,06$ \\
\hline 21. & $0,02(1)$ & 0,68 & $2,80(2)$ & 4,93(4) & 0,95 & 0,13 & $-0,08$ \\
\hline 22. & $4,51(1)^{*}$ & $-0,70$ & $7,36(2)^{*}$ & $0,91(4)$ & $-3,11^{* *}$ & $0,23^{*}$ & $-0,36$ \\
\hline 23. & $0,09(1)$ & 0,88 & $4,30(2)$ & $19,42(4)^{* *}$ & $-2,00^{*}$ & $0,23^{*}$ & 0,52 \\
\hline 24. & $0,87(1)$ & $-1,06$ & $1,79(2)$ & $0,63(4)$ & $-0,97$ & 0,09 & $-1,53$ \\
\hline
\end{tabular}

Notas: $\chi^{2}$ : Chi cuadrado; t: puntaje de la prueba T de Student; $\chi^{2} /$ Coef.: se indica Chi Cuadrado o Coeficiente de Contingencia según corresponda; ${ }^{* *} \mathrm{p}<.01 ;{ }^{*} \mathrm{p}<.05$.

Fuente: Autor.

como problema' y 'Problemas vinculados con la comercialización y los mercados'. La media de edad de quienes mencionan el primer problema es de 41,19 años mientras que la de quienes no lo hacen es de 43,99 . Por su parte, quienes destacan dificultades vinculadas con la comercialización y el mercado poseen en promedio 43,94 años, frente a 40,95 de quienes no lo hacen. Lo extraño de esto es que estas mismas asociaciones no se encuentran en el caso de la experiencia de los extensionistas, por lo que estas relaciones deberían explicarse a partir de la edad en sí misma, sin hacer referencia a la experiencia de los encuestados. Esto podría sugerir que se trata de una cuestión generacional, estando los técnicos más jóvenes más predispuestos a responsabilizar al productor de las problemáticas encontradas y aquellos de mayor edad más interesados o más atentos a dificultades de mercado.

Por otra parte, la región en la que trabajan los encuestados se relaciona con la referencia a problemáticas vinculadas con políticas e instituciones de desarrollo rural. Aquí, frente a una media de $67 \%{ }^{2}$ de referencia a esta área, encontramos una menor mención en Pampeana

2. Algunos porcentajes pueden variar levemente de los indicados en las tablas 1 y 2 ya que en los casos donde se indaga la relación entre variables, los porcentajes se toman en relación a quienes respondieron a la segunda variable utilizada para el análisis 
(56\%) y Cuyo (57\%), frente al resto de las regiones, donde se hace referencia a esta área con bastante mayor frecuencia (NOA: 70\%, NEA: $78 \%$, Patagonia: $92 \%$ ). Podría pensarse que esto se debe, por un lado, a un mayor interés de los encuestados en lo que son las políticas públicas de apoyo a los productores por tratarse de regiones de menor desarrollo productivo y/o productividad. Y por el otro, a la incidencia negativa de dinámicas políticas relacionadas con propuestas asistencialistas/clientelares por la existencia de mayores niveles de pobreza.

Finalmente, también el título académico se asocia a dos áreas problemáticas. En primer lugar, se asocia al área problema referida a las políticas e instituciones de desarrollo rural. Siendo la media de encuestados que habla de estos problemas el $67 \%$, con un porcentaje claramente menor aparecen quienes no poseen título universitario $(42 \%)$ y con uno superior quienes se ubican dentro de las ciencias sociales $(81 \%)$. Entonces, resulta coherente afirmar que el perfil de formación es relevante a la hora de identificar o comprender las problemáticas relacionadas con el trabajo de extensión. Segundo, el título académico de los encuestados también se relaciona con el área problema comercialización y mercados. En este caso, frente a una media de referencias a este tema del $40 \%$, los ingenieros agrónomos, los profesionales de las ciencias sociales y los que provienen de disciplinas categorizadas como 'otras' poseen un porcentaje algo más alto. En cambio, aquellos que no poseen formación universitaria poseen un 19\% y los veterinarios un $12 \%$. Esto sugiere que en el área pecuaria, más referida a la labor de los veterinarios, la problemática de comercialización es menos significativa. Por otra parte, se repite aquí la menor mención a este problema de parte de quienes no poseen formación universitaria, lo que simplemente podría explicarse por menos referencia a problemas en sus encuestas o, incluso, a respuestas más cortas.

Haciendo foco ahora en los problemas específicos mencionados por más del 10\% de los encuestados, se observa que en torno a la variable sexo existen diferencias estadísticamente significativas respecto de los problemas 1, 3, 19 y 22. En el caso del problema 1, referido a la falta de asociaciones de productores, a su debilidad y al individualismo y la desconfianza, claramente se trata de una cuestión mencionada más por las mujeres que por los hombres, ya que las primeras lo hacen en el $57 \%$ de los casos mientras que los hombres en el $41 \%$. Lo mismo sucede con las referencias a la falta de apoyo público o institucional, incluyendo la falta de políticas de desarrollo rural, área destacada por el $36 \%$ de la mujeres frente al $21 \%$ de los hombres. Si bien los porcentajes bajan, las mujeres resaltan como problema la falta de servicios públicos más del doble que los hombres ( $18 \%$ en el caso de las mujeres frente al $8 \%$ en los hombres). Finalmente, las mujeres también mencionan más el hecho de la complejidad del trabajo de extensión rural y la falta de equipos interdisciplinarios (17\% versus $8 \%$ ). En un trabajo previo (LANDINI, 2013b), se destacó la existencia de perfiles diferenciales entre hombres y mujeres en cuanto a la formación y a las áreas de desempeño en el contexto de la extensión, encontrándose en Argentina una mayor incidencia de mujeres extensionistas provenientes de las ciencias sociales y dedicadas al área socio-organizativa. Esto podría estar relacionando con la mayor cantidad de menciones de problemas referidos al trabajo con grupos y a una mayor conciencia de la complejidad y multidimensionalidad de la tarea de extensión. Por otra parte, también habría que prestar atención para ver si efectivamente se trata de diferencias asociadas al sexo y no a otras variables como la institución de pertenencia (siendo que la SAF posee mayor porcentaje de mujeres que el INTA) o como la formación profesional específica.

En cuanto a la variable edad, se observa que a menor edad, más referencias a los problemas 14, escasa participación y apropiación de proyectos por parte de los productores y 18, emigración a las zonas urbanas, especialmente de jóvenes. Respecto del primer problema, puede pensarse que los extensionistas más experimentados 
cuentan con mayores herramientas prácticas para lidiar con estos contratiempos, razón por la cual mencionan menos este problema. Esto se vería avalado por una mayor orientación al diálogo y a la participación de los extensionistas con mayor edad y experiencia (al menos para el caso paraguayo, LANDINI, BIANQUI y CRESPI, 2013). No obstante, también podría argumentarse que se trata de profesionales con una formación más tradicional, más asociados a enfoques difusionistas o transferencistas, que ponen menor atención en variables relacionadas con factores sociales que inciden en la extensión. De cualquier manera, esta última alternativa no parece encontrar apoyo ni en la experiencia de trabajo con extensionistas ni en la bibliografía consultada. Respecto de la problemática de la emigración, no se cuenta con interpretaciones para dar sentido al hecho de que a mayor edad, los extensionistas refieran menos este problema.

En el análisis realizado también se observó que cuatro problemas no se distribuían de manera similar en los extensionistas de las instituciones categorizadas: INTA, ProHuerta y SAF. Respecto del problema 3, falta de apoyo público o de políticas de desarrollo rural, se observan mayor cantidad de referencias en la SAF (41\%) frente a ProHuerta (26\%) e INTA (20\%). Sobre el número 10, referido a la existencia de dinámicas territoriales clientelares y de prácticas asistencialistas de parte del gobierno y otras instituciones, también se observan más referencias en el caso de la SAF (29\% de los extensionistas de la institución) frente a ProHuerta $(20 \%)$ e INTA $(12 \%)$. Respecto a los problemas de falta de infraestructura (extrapredial) para el desarrollo de la actividad productiva (problema 15), también se observa una mayor incidencia en el caso de la SAF (24\%) frente a ProHuerta $(11 \%)$ e INTA (9\%). Finalmente, en cuanto al problema de la falta de equipos interdisciplinarios y de la complejidad del trabajo de extensión (problema $22)$, se observa una mayor presencia en el caso de la SAF y de INTA (ambas con 15\%) frente al ProHuerta (3\%).

Analizando este perfil, es posible explicar una mayor referencia a problemas de falta de apoyo institucional y de políticas de desarrollo, de incidencia de prácticas clientelares y asistenciales, y la falta de infraestructuras para la producción en los extensionistas de la SAF a partir de su mayor articulación con instituciones o reparticiones gubernamentales locales y provinciales. Ciertamente, esto los acerca más a problemas vinculados con dinámicas políticas de índole clientelar o asistencial. No obstante, se trata de una interpretación débil que exige análisis ulterior, ya que dentro de la perspectiva de desarrollo señalada como hegemónica en la actualidad en el INTA, la articulación institucional y el abordaje territorial también constituyen elementos destacados. Finalmente, la menor referencia de los agentes de ProHuerta a la complejidad de la tarea de extensión rural y a la necesidad de equipos interdisciplinarios, bien puede deberse a las especificidades de su labor, focalizada en la capacitación y en la entrega de insumos biológicos, comparada con la de INTA y SAF. En efecto, estas dos instituciones incorporan formación y acompañamiento de grupos con persistencia a lo largo del tiempo y trabajo con tecnologías de mayor escala y complejidad.

Respecto de las diferencias regionales, frente a un promedio nacional de menciones del problema 3 referido a falta de apoyo público o institucional del 26\%, encontramos regiones como Patagonia (54\%), Cuyo (43\%) y NOA $(33 \%)$ que poseen promedios mayores, mientras otras como NEA (22\%) y Pampeana (16\%) poseen porcentajes menores. En cuanto a la existencia de prácticas clientelares, asistencialistas o paternalistas (problema 10), se observan dos regiones que poseen porcentajes menores a la media nacional (que es del 19\%), como son Pampeana (8\%) y Cuyo (14\%), y dos con porcentajes superiores (NEA 35\% y Patagonia 31\%). Por su parte, NOA se encuentra cerca de la media $(20 \%)$. En cuanto a la emigración como problema, particularmente de jóvenes (problema 18), se observa mayor incidencia en Patagonia (31\%), Cuyo (21\%) y NEA (20\%), frente a indicadores menores a la media en NOA $(8 \%)$ y Pampeana $(4 \%)$. Por su parte, respecto del problema 20 referido a problemas de 
salud de la población rural y falta de cobertura adecuada en las áreas de salud, educación o vivienda, ante una media a nivel país del $11,21 \%$, se destaca un porcentaje mucho más alto en la región NEA $(30,43 \%)$ y uno bastante más bajo en la Pampeana $(3,75 \%)$. Finalmente, en cuanto a la falta de recursos para el trabajo de extensión (problema 23), se observan mayores problemas en Patagonia (38\%) y NEA (17\%), frente a NOA $(11 \%$, que es también el promedio de la muestra total), Cuyo (7\%) y Pampeana (2\%).

$\mathrm{Si}$ bien para una lectura en detalle sería necesaria una evaluación profunda de las dinámicas políticas y económicas de las diferentes regiones, puede señalarse que la región Pampeana siempre tiende a ubicarse como territorio con menor incidencia de las problemáticas identificadas aquí, vinculadas en su mayoría a las dinámicas políticas y a la disponibilidad de recursos. En este sentido, podría argumentarse que esto se debe a que la región Pampeana constituye el territorio más rico del país, lo que puede sugerir tanto una mayor disponibilidad de recursos públicos para el trabajo de extensión como el trabajo con productores que poseen más recursos económicos propios a su disposición, lo que no los hace tan dependientes de las ayudas públicas. En contrapartida, en regiones más pobres como NOA y NEA, los problemas mencionados tienden a ser referidos con mayor frecuencia. Por su parte, para interpretar correctamente el caso de la Patagonia, posiblemente se requiera de un análisis particular, relacionado con las condiciones climáticas, productivas e institucionales específicas de la región. En efecto, siendo una región con ingresos per cápita relativamente altos, en varios casos tiende a aparecer con porcentajes similares a los de regiones más pobres.

Sobre la relación del nivel educativo con las distintas problemáticas, aquellos extensionistas con mayor educación tienden a destacar con mayor frecuencia las dificultades para articularse con los mercados (problema 2), la complejidad del campo de la extensión (problema 22) y la falta de recursos económicos para llevar adelante el trabajo (problema 23). Podría pensarse que la percepción de la complejidad de la tarea de extensión puede relacionarse con la realización de postgrados en el área de extensión o desarrollo rural, característicos en los extensionistas (LANDINI, 2013b), los cuales permiten una mayor visualización de esta complejidad. No obstante, estas relaciones entre nivel educativo y la mención de problemáticas en áreas específicas no parecen tener una explicación relativamente transparente.

Por su parte, existen numerosas relaciones entre los problemas mencionados por los extensionistas encuestados y su formación universitaria. En cuanto a las referencias a dificultades vinculadas con la falta de asociaciones (problema 1), se observa que quienes más los destacan son los profesionales de las ciencias sociales $(75 \%)$, mientras que aquellos que lo hacen menos son los que no tienen título universitario (29\%), ubicándose el resto relativamente cerca del promedio $(46 \%)$. Esto seguramente se relaciona tanto con las funciones específicas que desempeñan los profesionales de las ciencias sociales como con su percepción de cuestiones referidas a áreas sociales como el trabajo asociativo, siendo más oscura la explicación del caso de quienes no poseen estudios universitarios. En relación a los problemas para articularse con los mercados (problema 2), se destaca una mayor presencia en profesionales de las ciencias sociales (44\%) frente a una media del $26 \%$. Por su parte, se observan porcentajes menores a la media en el caso de quienes no poseen formación universitaria $(6 \%)$ y de los veterinarios $(6 \%)$. El resto está cerca del promedio. Parece razonable esta distribución teniendo en cuenta que quienes provienen de las ciencias sociales suelen trabajar en el área socioorganizativa, más vinculada con la asociación de productores en relación a la búsqueda de una mejor vinculación con los mercados, lo que da al problema mayor presencia. Por su parte, en el caso de los veterinarios, el menor porcentaje puede explicarse en relación a la mayor facilidad para la venta de ganado que de productos agrícolas 
Sobre la cuestión de la falta de apoyo público o institucional y la falta de políticas públicas para el desarrollo rural (problema 3), se observa una mayor incidencia en profesionales de las ciencias sociales $(56 \%)$ frente al promedio $(27 \%)$. En contrapartida, tanto quienes no poseen educación universitaria (13\%) como aquellos con estudios veterinarios $(20 \%)$ se caracterizan por menores porcentajes. En este caso, otra vez, los del ámbito de las ciencias sociales, al tender a percibir con mayor agudeza la articulación sociopolítica de la dimensión tecno-productiva, destacan problemáticas vinculadas con el área de las políticas públicas y del apoyo de las instituciones gubernamentales en los procesos de desarrollo rural.

En cuanto al problema 12, referido a la falta de escala de la producción, tema relacionado con las posibilidades de comercialización, llama la atención la falta de referencias en el caso de los profesionales de las ciencias sociales $(0 \%)$, frente a una media del $15 \%$, ya que anteriormente se ha argumentado que éstos tienen particular relación con el área socio-organizativa, asociada con el tema de mercados. Tal vez, la nula mención de problemáticas de volumen se deba a una concepción de la comercialización más basada en la cuestión de los intereses y las pujas de poder entre diversos actores que en una cuestión de escala. Por su parte, también se observan porcentajes menores a la media en el caso de quienes no tienen formación universitaria $(6 \%)$ $\mathrm{y}$ mayores en quienes han sido categorizados dentro de 'otras profesiones' (39\%). Respecto de la falta de infraestructura extrapredial para la producción (incluyendo la falta de caminos) (problema 15), los ingenieros agrónomos tienden a mencionar algo menos este problema que otras profesiones (9\% frente a una media del 14\%), mientras que los cientistas sociales $(25 \%)$ y otros profesionales $(19 \%)$ superan la media, siento dudosas las razones que podrían justificar estos porcentajes.

Respecto del señalamiento de la falta de equipos interdisciplinarios y la complejidad del campo de la extensión (problema 22), se trata de una dificultad mencionada más por los veterinarios $(31 \%)$, ubicándose los agrónomos $(12 \%)$ cerca de la media $(11 \%)$, mientras que el resto de las categorías poseen porcentajes menores (ningún título 3\%, ciencias sociales $7 \%$ y otros profesionales $0 \%$ ). Interesante el caso de la media mayor en el caso de los veterinarios, ya que esto podría estar indicando una mayor dificultad para lidiar con esta complejidad que la otra profesión técnica característica, como son los agrónomos. Finalmente, en cuando al problema 23, la falta de recursos económicos para el trabajo de extensión, se trata de una cuestión particularmente destacada por los profesionales de las ciencias sociales $(31 \%)$ frente a una media del $11 \%$, similar a los porcentajes de los agrónomos (11\%) y los veterinarios (12\%), mientras que aparecen porcentajes menores en el caso de aquellos sin título universitario (0\%) y con otra formación profesional (6\%).

En líneas generales, el análisis de la relación entre la formación profesional y los problemas encontrados por los técnicos en su trabajo de extensión muestra que la formación universitaria de los profesionales es determinante en cuanto a los problemas percibidos en su práctica, ya que es la variable que ha reportado mayores relaciones estadísticamente significativas respecto de las otras analizadas. Así, queda claro que cada profesión percibe su tarea tanto desde su formación como desde las prácticas específicas a las que es orientado por ella. Asimismo, en líneas generales, quienes poseen formación en ciencias sociales parecen presentar descripciones de los problemas bastante propias, cuando profesiones más tradicionales como los agrónomos y veterinarios (que de hecho constituyen la mayor parte de la muestra) suelen acercarse a la media. Por su parte, resulta llamativo que quienes no poseen formación universitaria tiendan a presentar de manera sistemática una menorincidencia de los problemas aquíanalizados. Esto puede deberse a diferentes razones, como la función específica que desempeñan dentro de las instituciones, una menor actitud crítica o una simple tendencia a responder de manera más acotada a las preguntas de la encuesta. 
En relación a la variable experiencia en el trabajo de extensión, se observa que quienes han trabajado durante más tiempo como extensionistas mencionan de manera más frecuente la falta de volumen o de escala en la producción (problema 12), lo que podría deberse tanto a una mayor conciencia de la importancia de esta problemática, como al perfil de formación profesional que puedan tener estos profesionales.

\section{Reflexiones finales}

En este artículo, a partir de una encuesta realizada a extensionistas que trabajan en el sistema argentino de extensión rural público, se identificaron los principales problemas con los que estos agentes se encuentran en su trabajo. El conocimiento de cuáles son estos problemas y cuál es su importancia relativa constituye una información sencilla, clara y cuantificada que puede ser utilizada para el diseño de políticas públicas en el ámbito de la extensión y el desarrollo rural, al identificarse áreas que deben ser atendidas y sobre las que resulta necesario generar acciones concretas. Tomando los cinco problemas más mencionados, se reconoce como necesario (a) repensar tanto las expectativas de los programas como el modo de trabajo con grupos de productores, (b) no focalizar sólo en la dimensión socio-productiva sino atender también de manera constitutiva los problemas de comercialización, (c) abordar la problemática de tierras y (d) asegurarse una planificación de manera articulada con los beneficiarios y sus organizaciones. En esta línea, a nivel de políticas públicas de apoyo, resulta fundamental plantear la comercialización y la disponibilidad de tierra como cuellos de botella para el desarrollo de la agricultura familiar. Atendiendo al caso de Brasil, la revisión bibliográfica realizada sugiere que varios de estos problemas también podrían tener allí gran importancia. Esto lleva a considerar que estas propuestas, si bien referidas a Argentina, también podrían tener valor en ese contexto.
Por su parte, a nivel de las instituciones públicas que gestionan la extensión rural en la Argentina, estos resultados también resultan de utilidad tanto para diseñar proyectos y estrategias de intervención en el territorio como para organizar los contenidos y modalidades de capacitación y actualización de sus extensionistas. En particular, a este nivel corresponde repensar las estrategias de acción que involucran el trabajo con grupos de productores asociados y la búsqueda de alternativas para lograr una mayor participación de los beneficiarios en las iniciativas de extensión y desarrollo rural, algo que debe ser contemplado desde el diseño mismo de los proyectos. Asimismo, la identificación y jerarquización de estos problemas, también resulta un instrumento de utilidad para la tarea de investigación, ya que sugiere temáticas que deben ser abordadas y profundizadas por los investigadores, si es que se busca generar impacto en problemáticas concretas y reales.

Por otra parte, el listado generado, así como la descripción cualitativa de los problemas a los que se enfrentan los extensionistas rurales, muestran nuevamente que la tarea de extensión no es exclusivamente técnica, sino que incluye una multiplicidad de dinámicas, factores y niveles, los cuales exceden cualquier tipo de formación, tanto técnica como social. En esta línea, y teniendo en cuenta el interés del autor por generar una Psicología del Desarrollo Rural (LANDINI, 2010, 2011; LANDINI, LEEUWIS, LONG y MURTAGH, en prensa), este listado problemático también demuestra que numerosos problemas a los que se enfrentan los extensionistas en su práctica poseen un fuerte contenido psicosocial, lo que justifica un mayor involucramiento de la psicología.

Otro aspecto a destacar es que, pese a que en el análisis histórico del INTA se asume la existencia de modelos de extensión y desarrollo rural hegemónicos en cada período, también es necesario considerar la posible persistencia de estructuras y prácticas institucionales de períodos anteriores dentro de las dinámicas actuales de cualquier institución. Así, se observa 
un porcentaje importante de extensionistas que parten de una concepción difusionista o rogeriana de los productores que tiende a describirlos como reticentes, atrasados y poco propensos a la adopción de riesgos, o de una finalidad transferencista de la extensión rural, propias de la primera y segunda etapa del INTA respectivamente. Así, pese a la existencia de visiones del desarrollo rural hegemónicas a nivel institucional, eso no debe hacernos perder de vista la existencia de una articulación sincrética con elementos que estuvieron consolidados en el pasado y que son incluso contrarios a las premisas actuales de la práctica de extensión. Por otra parte, si bien el análisis empírico realizado abordó sólo al caso argentino, la revisión bibliográfica referida a Brasil también sugiere allí la persistencia de prácticas difusionistas/transferencistas. Esto invita a analizar y profundizar en las razones de esta persistencia y en las alternativas para una transformación efectiva (y no solamente discursiva) de las prácticas de extensión.

Por otra parte, el análisis de asociación entre variables también mostró que los problemas detectados no se distribuyen de manera homogénea, existiendo diferencias a nivel de sexo, edad, institución de pertenencia, región donde se realizan las actividades de extensión, nivel educativo, título universitario y experiencia en el área de extensión. Si bien en cierto sentido estos resultados pueden percibirse como parciales o fragmentarios, también resultan de gran utilidad para adecuar las acciones orientadas a enfrentar estos problemas según el perfil de los extensionistas, del territorio o de las instituciones en las que estos trabajan. Como los encuestados han señalado, las propuestas que bajan desde ámbitos centrales sin oportunidad de que sean adecuadas a cada contexto no parecen ser una buena alternativa.

Finalmente, también resulta necesario recordar que estos resultados han sido obtenidos a partir de una muestra intencional, lo que no garantiza que sea representativa del total nacional. Además, el estudio sólo tomó el punto de vista de un actor específico: los extensionistas. Es indudable que la misma estrategia, aplicada a otros actores como productores, autoridades institucionales o referentes académicos, hubiera generado un resultado diferente. Estos hechos no menoscaban los resultados obtenidos pero sí invitan a tomarlos con cautela.

\section{Bibliografía}

ALEMANY, C. Apuntes para la construcción de los períodos históricos de la Extensión Rural del INTA. En THORNTON, R. y CIMADEVILLA, G. (Eds.) La extensión rural en debate. Concepciones, retrospectivas, cambios y estrategias para el MERCOSUR. Buenos Aires: INTA, p. 137-171, 2003.

ALMEIDA, S., OLIVEIRA, M. y XAVIER, J. A descentralização da política nacional de ATER: uma experiência nos assentamentos de reforma agrária no noroeste mineiro - Brasil. Sociedade E Natureza, 22 (3), p. $551-560,2010$.

AQUINO, J. y TEIXEIRA, O. Agricultura familiar, crédito e mediação institucional: A experiência do PRONAF em São Miguel no nordeste brasileiro. Cuadernos de Desarrollo Rural, 54, p. 61-85, 2005.

ARDILA, J. Extensión rural para el desarrollo de la agricultura y la seguridad alimentaria: aspectos conceptuales, situación y una visión de futuro. San José, Costa Rica: IICA, 2010.

BOAS, A. y GOLDEY, P. A comparison on farmers' participation in farmers' organizations and implications for rural extension in Minas Gerais. Organizações Rurais $\mathcal{E}$ Agroindustriais, 7 (3), p. 259-270, 2005.

CÁCERES, D. Estrategias campesinas en sociedades rurales contemporáneas. Revista de la Facultad de Agronomía, 15 (1), p. 67-72, 1995.

CÁCERES, D. Dos estrategias de articulación entre técnicos y pequeños productores. Diferentes enfoques metodológicos y tecnológicos. Cuadernos de Desarrollo Rural, 57, p. 59-99, 2006.

CARBALLO, C. Extensión y transferencia de tecnología en el sector agrario argentino. Buenos Aires: Facultad de Agronomía de la Universidad de Buenos Aires, 2002.

CARBALLO, C. Viejos desafíos en un nuevo contexto para el desarrollo rural y Nacional. Ponencia presentada en XIII Jornadas Nacionales de Extensión Rural y V Jornadas del MERCOSUR, 2006.

CIMADEVILLA, G. Extensión y comunicación. Antecedentes, articulaciones y contrastes. En 
CIMADEVILLA, G. y CARNIGLIA, E. (Eds.) Comunicación, ruralidad y desarrollo. Mitos, paradigmas y dispositivos de cambio. Buenos Aires: INTA, p. 151-199, 2004.

CONDE, F. Un ensayo de articulación de las perspectivas cuantitativa y cualitativa en la investigación social. Reis: Revista Española de Investigaciones Sociológicas, 51, p. 91-117, 1990.

DA ROS, C. Gênese, desenvolvimento, crise e reformas nos serviços públicos de extensão rural durante a década de 1990. Mundo Agrario, 25, 2012.

DE SCHUTTER, A. Extensión y capacitación rurales. México: Trillas, 1982.

ELGUE, M. y CHIARADÍA, C. Formas asociativas para la agricultura familiar: elementos para el análisis funcional y normativo de las distintas formas jurídicas. Buenos Aires: Secretaría de Agricultura, Ganadería, Pesca y Alimentos, 2007.

FERNÁNDEZ, A. Unidos para exportar. Campo y Tecnología, 16, p. 19-21, 1994.

FREIRE, P. ¿Extensión o comunicación? La concientización en el medio rural. Buenos Aires: Siglo XXI, 1973.

GUBA, E. y LINCOLN, Y. Competing paradigms in qualitative research. En DENZIN, N. y LINCOLN, Y. (Eds.) Handbook of qualitative research. Londres: Sage, p. 105-117, 1994.

HENZ, G. Desafios enfrentados por agricultores familiares na produção de morango no Distrito Federal. Horticultura Brasileira, 28, p. 260-265, 2010.

LANDINI, F. Ingenieros extensionistas formoseños desde la mirada de los pequeños productores. Representaciones, expectativas y realidades. Mundo Agrario, 20, 2010 [versión online]

LANDINI, F. Income and use of money in the peasant economy. Contributions to rural development psychology from a case study. Journal of Alternative Perspectives in the Social Sciences, 3 (3), p. 674-703, 2011.

LANDINI, F. Perfil de los extensionistas rurales argentinos del sistema público. Mundo Agrario, 27, 2013a. [versión online]

LANDINI, F. Necesidades formativas de los extensionistas rurales paraguayos desde la perspectiva de su función, sus problemas y sus intereses. Trabajo y Sociedad, 20, p. 149-160, 2013b.

LANDINI, F., BIANQUI, V. y CRESPI, M. Evaluación de las creencias sobre extensión rural de los extensionistas paraguayos. Psiencia, 5 (1), 3-14, 2013.
LANDINI, F, MURTAGH, S. y LACANNA, M. Aportes y reflexiones desde la psicología al trabajo de extensión con pequeños productores. Formosa, Argentina: INTA, 2009

LANDINI, F. y MURTAGH, S. Prácticas de extensión rural y vínculos conflictivos entre saberes locales y conocimientos técnicos. Contribuciones desde un estudio de caso realizado en la provincia de Formosa (Argentina). Ra Ximhai, 7 (2), p. 263-279, 2011.

LANDINI, F., LEEUWIS, C., LONG, N. y MURTAGH, S. Towards a psychology of rural development processes and interventions. Journal of Community and Applied Social Psychology, en prensa. DOI: 10.1002/casp.2187

LAPALMA, A. El escenario de la intervención comunitaria. Revista de Psicología de la Universidad de Chile, 10 (2), p. 61-70, 2001.

LEEUWIS, C. Communication for rural innovation. Rethinking agricultural extension. Oxford: Blackwell, 2004.

LEEUWIS, C. y AARTS, N. Rethinking communication in innovation processes: creating space for change in complex systems. Journal of Agricultural Education and Extension, 17 (1), p. 21-36, 2011.

LELIS, D., COELHO, F. y DIAS, M. A necessidade das intervenções: Extensão rural como serviço ou como direito? Interações, Campo Grande, 13 (1), p. 69-80, 2012.

LOBOS, G. Micro-negocios asociativos campesinos: análisis económico de un sistema de producción ovina, región del Maule, Chile. Gestão \& Produção, 12 (2), p. 165-175, 2005.

MALFÉ, R. Fantásmata. El vector imaginario de procesos e instituciones sociales. Buenos Aires: Amorrortu, 1994.

MANZANAL, M. Estrategias de supervivencia de los pobres rurales. Buenos Aires: Centro Editor de América Latina, 1993.

MARINO, M. La extensión como proceso de educación. Presencia, 28, p. 6-7, 1993.

MCLEOD, W. y QAMAR, M. Agricultural extension, rural development and the food security challenge. Roma: FAO, 2003.

MEDEIROS, J. y BORGES, D. Participação cidadã no planejamento das ações da Emater-RN. Revista de Administração Pública, 41 (1), p. 63-81, 2007.

MÉNDEZ, M. Los retos de la extensión ante una nueva y cambiente noción de lo rural. Revista Facultad Nacional de Agronomía, Medellín, 59, p. 3407-3423, 2006.

SALVADOR, D. A modernição da atividade mandioqueira e uso atual do território do Agreste Portiguar. Mercator, 20, p. 93-117, 2010. 
SARAIVA, R. y CALLOU, A. Políticas públicas e estratégias de comunicação para o desenvolvimento local de comunidades pesqueiras de Pernambuco. Interações, Campo Grande, 10 (1), p. 73-81, 2009.

SCHALLER, N. Extensión rural: ihacia dónde vamos?, ihacia dónde ir? El Colorado, Argentina: INTA, 2006.

SCHEINKERMAN, E., FOTI M. y ROMÁN, M. Los pequeños productores en la República Argentina: importancia en la producción agropecuaria y en el empleo en base al censo nacional agropecuario 2002. Buenos Aires: Secretaría de Agricultura, Ganadería, Pesca y Alimentos, 2007.

SEPULCRI, O. y PAULA, N. O Estado e seus impacto na EMATER-PR. Revista Paranaense de desenvolvimento, 114, p. 87-110, 2008.

SILVA, F. y LEITÃO, M. Extensão rural e floricultura tropical para o desenvolvimento local: a cooperação no processo de inclusão competitiva dos agricultores familiares em Pernambuco. Interações, Campo Grande, 10 (1), p. 9-19, 2009.

SILVETTI, F. y CÁCERES, D. Una perspectiva sociohistórica de las estrategias campesinas del noreste de Córdoba, Argentina. Debate Agrario, 28, p. 103-127, 1998.

SOUZA, I. y GOMES, A.. Folkcomunicaçao e extensão rural brasileira: as estratégias de comunicação rural para o desenvolvimento local. Razón y Palabra, 60, 2008.

STAGE, O. y REKVE, P. Food security and food selfsufficiency: the economic strategies of peasants in eastern Ethiopia. The European Journal of Development Research, 10 (1), p. 189-200, 1998.

TAVEIRA, L. y OLIVEIRA, J. A extensão rural na perspectiva de agricultores assentados do Pontal do
Paranapanema-SP. Revista de Economia e Sociologia Rural, 45 (4), p. 9-30, 2008.

THORNTON, D. Os '90 e o novo século nos sistemas de extensao rural e transferencia de tecnología públicos no MERCOSUL. Buenos Aires: INTA, 2006.

TORT, M. Instalación del componente de 'Asociativismo' en el programa Cambio Rural. En VALENTINUZ, C., GUTIÉRREZ, O., THORNTON, R., TORT, M. y CARRAPIZO V. (Comp.) Metodologías de enseñanzaaprendizaje aplicadas a la extensión rural. Buenos Aires: INTA, p. 121-128, 2005.

TORT, M. Enfoques de la extensión rural. En nuestro agro: ¿Evolución, complementación u oposición. En BALSA, J., MATEO G. y OSPITAL, M. (Comp.) Pasado y presente en el agro argentino. Buenos Aires: Lumiere, p. $428-450,2008$.

TORT, M. y ROMÁN, M. Explotaciones familiares: diversidad de conceptos y criterios operativos. En GONZÁLEZ, M. (Ed.) Productores familiares pampeanos: hacia la comprensión de similitudes y diferenciaciones zonales. Buenos Aires: Astralib, p. 35-65, 2005.

TORT, M. y LOMBARDO, P. Asociativismo agrario: alternativa para los pequeños y medianos productores. Realidad Económica, 141, p. 93-102, 1996.

VAN WOERKUM, C. AARTS, N. y VAN HERZELE, A. Changed planning for planned and unplanned change. Planning Theory, 10 (2), p. 144-160, 2011.

ZUIN, L., ZUIN, P. y MANRIQUE, M. A comunicação dialógica como fator determinante para os processos de ensino-aprendizagem que ocorrem na capacitação rural: um estudo de caso em um órgão público de extensão localizado no interior do Estado de São Paulo. Ciência Rural, 41 (5), p. 917-923, 2011. 
